\title{
A RELAÇÃO ENTRE AS VARIÁVEIS MACROECONÔMICAS E 0 IBOVESPA: NOVAS EVIDÊNCIAS PARA O BRASIL
}

\section{THE RELATIONSHIP BETWEEN MACROECONOMIC VARIABLES AND IBOVESPA: NEW EVIDENCE FROM BRAZIL}

\section{RESUMO}

O objetivo desta pesquisa é verificar a relação entre as variáveis macroeconômicas e o índice Ibovespa, no período de janeiro de 2000 a fevereiro de 2019. Para tanto, utiliza-se como metodologia a estimação de um modelo Vetor de Correção de Erros (VEC), a função impulso resposta e o teste de causalidade de Granger. Os resultados mostram que a taxa básica de juros está negativamente associada com o Ibovespa e possui causalidade no sentido de Granger, com um nível de significância de $10 \%$, assim como uma relação positiva foi observada em relação à confiança dos agentes. O Produto Interno Bruto (PIB) não impactou positivamente o Ibovespa, diferentemente de outras aplicações empíricas, o que pode ser resultado do contexto macroeconômico do Brasil observado entre 2015 e 2019, de alta do mercado acionário ao meio de uma crise econômica. As estimativas mostraram também que as variáveis macroeconômicas respondem aos estímulos do mercado acionário, mostrando que o aumento deste possui impactos negativos no Câmbio e positivos no PIB e nas reservas internacionais. Conclui-se que o mercado de capitais é um provedor de recursos permanentes para a economia, uma vez que, a relação entre as variáveis macroeconômicas e o mercado acionário é estatisticamente significante. Dessa forma, este estudo contribui para a academia no sentido de identificar as melhores variáveis de controle nos modelos econométricos e pela determinação do Ibovespa como uma variável explicativa para o crescimento econômico dos países.

Palavras chave: Ibovespa, Variáveis macroeconômicas, Mercado de capitais.

\begin{abstract}
The objective of this research is to verify the relationship between macroeconomic variables and the Ibovespa index, considering the period from January 2000 to February 2019. For this purpose, the estimation of an Error Correction Vector (VEC) model is used as methodology., the impulse response function and the Granger causality test. The results show that the basic interest rate is negatively associated with the Ibovespa and has causality in the sense of Granger, with a significance level of $10 \%$, just as a positive relationship was observed in relation to the agents' confidence. The Gross Domestic Product (GDP) did not have a positive impact on the Ibovespa, unlike other empirical applications, which may be the result of the macroeconomic context in Brazil observed between 2015 and 2019, a rise in the stock market in the middle of an economic crisis. The estimates also showed that the macroeconomic variables respond to the stimulus of the stock market, showing that its increase has negative impacts on the exchange rate and positive impacts on GDP and international reserves. It is concluded that the capital market is a provider of permanent resources for the economy, since the relationship between macroeconomic variables and the stock market is statistically significant. Thus, this study contributes to the academy in order to identify the best control variables in econometric models and by determining Ibovespa as an explanatory variable for the economic growth of countries.
\end{abstract}

Keywords: Ibovespa, Macroeconomic Variables, Capital market.

\section{Luan Vinicius Bernardelli}

Professor da Universidade Estadual do Paraná (UNESPAR). Doutor Economia pela Universidade Estadual de Maringá. Foi Visiting Scholar na Southern Cross University. Mestre em Teoria Econômica pela Universidade Estadual de Maringá. Graduado em Ciências Econômicas pela Universidade Estadual do Norte do Paraná. Atua nas áreas de Economia monetária e financeira, Economia Regional, Economia da Religião e Economia da Saúde. Também atua como revisor ad hoc em diversos periódicos nacionais e internacionais. Contato: Av. Minas Gerais, 5021 - Núcleo Hab. Adriano Correia, Apucarana - PR, 86813010. E-mail: luanbernardelli@gmail.com

\section{Murilo Jose Borges}

Atualmente é funcionário do Banco do Brasil e professor do Centro Universitário Cidade Verde (UniFCV). Possui graduação em Ciências Econômicas (2003), Mestrado (2014) e Doutorado (2019) em Teoria Econômica pela Universidade Estadual de Maringá (UEM). Tem experiência na área de Economia, com ênfase em Economia Bancária e Financeira, atuando principalmente nos seguintes temas: certificações de investimentos, economia monetária, estatística e econometria. Contato: Av Duque de Caxias, $n^{\circ}$ 448, Maringá-PR, CEP: 87013 180. E-mail: murilo_borges@hotmail.com

\section{Simone Leticia Raimundini Sanches}

Doutora em Administração pela Universidade Federal do Rio Grande do Sul (UFRGS). Mestre em Administração pela Universidade Estadual de Maringá (UEM), Graduada em Ciências Contábeis pela Universidade Estadual de Maringá (UEM). Docente do curso de Ciências Contábeis e do Programa de Pós-Graduação em Ciências Contábeis na Universidade Estadual de Maringá (UEM). Contato: Av. Colombo, 5790, Bloco C23, sala 003, Maringá, PR, CEP 87020-900. E-mail: slraimundini@uem.br

\section{Eliane Araújo}

Doutora em Administração pela Universidade Federal do Rio Grande do Sul (UFRGS). Mestre em Administração pela Universidade Estadual de Maringá (UEM), Graduada em Ciências Contábeis pela Universidade Estadual de Maringá (UEM). Docente do curso de Ciências Contábeis e do Programa de Pós-Graduação em Ciências Contábeis na Universidade Estadual de Maringá (UEM). Contato: Av. Colombo, 5790, Bloco C23, sala 003, Maringá, PR, CEP 87020-900. E-mail: slraimundini@uem.br

\section{Gustavo Henrique Leite de Castro}

Doutorando em Economia pela Universidade de São Paulo (USP). Mestre em Economia Regional pela Universidade Estadual de Londrina (UEL). Bacharel em Ciências Econômicas pela Universidade Estadual do Norte do Paraná (UENP). E-mail: gustavocastro@usp.br 


\section{INTRODUÇÃO}

O desenvolvimento dos mercados financeiros foi essencial para a evolução do sistema de troca e a alocação eficaz dos recursos entre os agentes superavitários e os deficitários. Um exemplo histórico dessa relação é dado pela Europa e os Estados Unidos da América (EUA), os quais foram impulsionados pela elevação na eficiência da intermediação da poupança, proporcionada pela sofisticação do mercado financeiro de capitais (Grôppo, 2004).

A partir da visualização desses conceitos, existe uma crescente demanda de estudos sobre o comportamento do mercado de capitais em contabilidade para as análises fundamentalistas, valuation, testes de eficiência de mercado, dentre outros, em que o aspecto macroeconômico se revela pertinente a nível stricto sensu para tais análises (Kothari, 2001). Assim, observa-se uma integração entre o mercado financeiro e o mercado produtivo, em que o bom desempenho macroeconômico faz com que as empresas sejam beneficiadas e suas ações mais demandadas (Singh, Mehta \& Varsha, 2011).

No Brasil, essa integração pode ser associada com a variação do valor real das empresas listadas na bolsa de valores, nesta pesquisa, corresponde ao Ibovespa, e o crescimento do Produto Interno Bruto (PIB) do país, uma vez que em 2000 o valor real das empresas listadas no Ibovespa, à preços de 2000, era de R $\$ 250$ bilhões, em 2017 aproximou-se dos $\mathrm{R} \$ 700$ bilhões. Da mesma forma, o PIB obteve um crescimento médio no período 2000-2017 de 2,47\%. Contudo, ao se restringir ao período de 2017, essa relação pode ser questionada, pois, enquanto o valor das empresas cresceu $24,53 \%$ apenas nos 10 primeiros meses de 2017, o PIB apresentou resultados negativos (Bacen, 2019).

Nesse contexto, investidores, policymakers, empresários e demais agentes econômicos tem interesse em compreender como a economia e o mercado de capitais se relacionam. Ademais, a interligação do mercado financeiro com o desempenho econômico das nações é uma temática analisada em diferentes países, com diferentes abordagens metodológicas e distintos períodos de tempo, como por exemplo, os estudos clássico de Geske e Roll (1983) para os EUA, Mukherjee e Naka (1995) para o Japão e Sich (2010) para a Índia. O interesse em estudar esta relação decorre do fato de que o mercado financeiro pode estimular a produção de bens e serviços, por meio da intermediação eficiente dos recursos financeiros entre os agentes (Grôppo, 2004) e, assim, elevar o nível de bem-estar de toda sociedade, uma vez que os potenciais investidores desse mercado é um grupo composto por diversas classes da sociedade, isto é, os retornos são distribuídos em distintas classes sociais (Aga \& Kocaman, 2006). De modo que o desenvolvimento do mercado de capitais e da economia fomentam a pesquisa e a prática contábil (Kothari, 2001). O fato é que as variáveis macroeconômicas exercem papel primordial nessa relação, como já retratado por Grôppo, (2004); Grôppo, (2005); Oliveira, (2006); Junior e Higuchi (2008), Oliveria e Frascaroli, (2014); Bernardelli e Bernardelli, (2016); Da Silva Ribeiro, Leite e Justo (2016); Bernardelli, Bernardelli e Castro, (2017), Machado, Gartner e Machado (2017) e Bernardelli e Castro (2020).

Atrelado a este arcabouço de ideias, este estudo proporciona novas evidências, como a de que, por exemplo, o Ibovespa é uma variável importante na análise dos indicadores econômicos, uma vez que o mercado de capitais mostrou impacto sobre as variáveis macroeconômicas. O ineditismo deste estudo também ocorre pelo avanço nas análises das novas varíaveis macroeconômicas, como o índice de confiança e as reservas internacionais, sugeridos por Grôppo (2005); Pimenta Junior e Higuchi (2008), Da Silva Ribeiro, Leite e Justo (2016) e Machado, Gartner e Machado (2017). Adicionalmente, este trabalho apresenta uma estimação empírica recente da relação entre as variáveis macroeconomicas e o Ibovespa.

Assim, o objetivo desse trabalho é verificar a relação entre as variáveis macroeconômicas e o índice Ibovespa, no período de 2000 a 2019. Portanto, estabelece-se as seguintes hipóteses: (i) as variáveis macroeconômicas causam a variação do índice Ibovespa; (ii) as variáveis macroeconômicas explicam a variação do Ibovespa e (iii) o comportamento das empresas listadas no Ibovespa é relevante na análise das variáveis macroeconômicas.

Quanto a metodologia empregada neste trabalho, realizou-se uma abordagem teórico e empírica. Na parte empírica, a partir dos dados coletados, foi construído um banco de dados para que a análise econométrica fosse implementada. A partir disso, foram aplicadas as técnicas econométricas relacionadas ao modelo de Vetor de Correção de Erros (VEC), a função impulso resposta e o teste de causalidade de Granger.

Para atender os objetivos estabelecidos, este trabalho está dividido em três seções. Além desta introdução e das considerações finais, a segunda seção apresenta a fundamentação teórica e empírica sobre a relação das variáveis macroeconômicas com o mercado acionário, a terceira apresenta a base de dados, a metodologia utilizada e justifica a identificação dos Vetor de Correção de Erros (VEC) e a quarta apresenta os resultados da pesquisa e os relaciona com o embasamento teórico da seção dois e a quinta seção apresenta as considerações finais deste trabalho.

\section{A MACROECONOMIA E O MERCADO DE CAPITAIS}

A abordagem da economia neoclássica entende que a intermediação financeira desempenha um papel passivo nas variáveis macroeconômicas, no sentido de apenas canalizar a poupança das famílias para os investidores, seu comportamento pouco afeta a determinação das condições de financiamento da economia (Gurley \& Shaw, 1995). Para Fama (1980), a intermediação financeira é passiva na determinação de preços e das variáveis reais da economia, ou seja, no emprego e na renda. Essa visão é contestada teoricamente por alguns autores, em especial, por Keynes (1988), que destacou o papel do mercado financeiro, principalmente dos bancos, na provisão de liquidez necessária, via crédito, para a realização do investimento e, consequentemente, o crescimento econômico ${ }^{1}$.

1 Ver também Minsky (1986). 
Entretanto, a estrutura financeira não está baseada apenas no setor bancário, mas também pode estar baseada no mercado de capitais. Paula (2014) enfatiza que a experiência dos países desenvolvidos mostra que não existe um modelo de sistema financeiro ideal quanto ao relacionamento com as variáveis macroeconômicas, pois as características histórico-institucionais moldaram o desenvolvimento do sistema financeiro de modo a atender as especificidades de cada país.

Ainda que estudos comprovem que o sistema financeiro brasileiro é orientado pelo sistema bancário, não é razoável omitir a importância do mercado acionário. Neste caso, o Ibovespa para o Sistema Financeiro Nacional. Assim, o mercado de capitais assume papel relevante no desenvolvimento econômico, pois, por meio de diversas modalidades de financiamentos a médio e longo prazo para capital de giro e capital fixo é municiador de recursos permanentes para a economia (Assaf Neto, 2017).

Com base nesta contextualização sobre o papel do mercado financeiro e o mercado de capitais, Singh et al. (2011) ressaltam que há uma atenção crescente na relação entre o mercado de acionário e a macroeconomia, mais especificamente, entre os preços das ações e as políticas macroeconômicas, estimulando a elaboração de pesquisas neste segmento.

O objetivo do investidor ao ingressar no mercado acionário consiste em obter um retorno condizente com o custo de oportunidade e o risco implícito do ativo e, dessa forma, os investidores consideram simultaneamente um conjunto de variáveis financeiras e não financeiras antes de tomar sua decisão (Aga \& Kocaman, 2006). Portanto, acontecimentos econômicos possuem diferentes impactos no mercado de capitais, dependendo se a consequência abrange horizontes de curto ou de longo prazo (Engle, Ghysels, Sohn, 2013).

Diante da relevância do assunto e de estudos empíricos que corroboraram com a existência de relação entre variáveis macroeconômicas e mercado de capitais, o Quadro 1 apresenta uma síntese, não exaustiva, da literatura empírica.

Quadro 1 - Resumo da literatura empírica

\begin{tabular}{|c|c|c|c|}
\hline $\begin{array}{l}\text { Autores (ano), } \\
\text { Pais e Periodo }\end{array}$ & Variáveis & Método & Resultado \\
\hline $\begin{array}{c}\text { Geske e Roll (1983) - EUA } \\
(1947-1980)\end{array}$ & $\begin{array}{l}\text { 1. Ganhos coorporativos; } 2 \text {. } \\
\text { Taxa de desemprego; } 3 \text {. Taxa de } \\
\text { Juros; 4. Inflação; }\end{array}$ & Arima e MQO & $\begin{array}{l}\text { Um choque real (descontada a taxa de } \\
\text { inflação do período) negativo aleatório afeta } \\
\text { os retornos das ações, resultando em maior } \\
\text { desemprego e menor ganhos coorporativos }\end{array}$ \\
\hline $\begin{array}{c}\text { Darrat e Mukherjee (1986) } \\
\text { Índia } \\
(1948-1984)\end{array}$ & $\begin{array}{l}\text { 1. Oferta monetária; } 2 \text {. Taxa de } \\
\text { Juros de curto e longo prazo; } 3 \text {. } \\
\text { PNB per capita; } 4 \text {. Inflação; }\end{array}$ & VAR & $\begin{array}{l}\text { Há defasagem significativa entre os retornos } \\
\text { dos ativos e o crescimento da oferta } \\
\text { monetária; Há relação negativa entre retorno } \\
\text { dos ativos e taxa de juros de longo prazo e } \\
\text { inflação. }\end{array}$ \\
\hline $\begin{array}{l}\text { Mukherjee e Naka } \\
\text { (1995) } \\
\text { Japão } \\
(1971-1990)\end{array}$ & $\begin{array}{l}\text { 1. Taxa de câmbio; } 2 \text {. Oferta de } \\
\text { moeda; 3. Inflação; } 4 \text {. Produção } \\
\text { industrial; } 5 \text {. Taxa de longo prazo } \\
\text { dos títulos do governo; }\end{array}$ & VEC & $\begin{array}{l}\text { Há relação negativa entre o mercado } \\
\text { acionário, a taxa de inflação e a taxa de longo } \\
\text { prazo dos títulos do governo; Há relação } \\
\text { positiva entre o mercado acionário e a taxa de } \\
\text { câmbio, oferta de moeda, produção industrial } \\
\text { e call money rate. }\end{array}$ \\
\hline $\begin{array}{c}\text { Gjerde e Sættem (1999) } \\
\text { Noruega } \\
(1974-1994)\end{array}$ & $\begin{array}{c}\text { 1. Produção industrial; } 2 \text {. } \\
\text { Consumo; } 3 \text {. Inflação; } 4 \text {. Taxa } \\
\text { de câmbio; 5. Preço do barril } \\
\text { do petróleo; } 6 \text {. Taxa de Juros; } 7 \text {. } \\
\text { Índice produção industrial OCDE }\end{array}$ & $\begin{array}{l}\text { VAR e } \\
\text { Causalidade de } \\
\text { Granger }\end{array}$ & $\begin{array}{c}\text { Os retornos das ações apresentaram uma } \\
\text { resposta positiva em relação à produção } \\
\text { industrial e uma resposta negativa às } \\
\text { mudanças nas taxas de juros reais; as } \\
\text { mudanças na taxa de juros reais afetam } \\
\text { negativamente a inflação e os retornos de } \\
\text { ações; o retorno das ações respondeu com } \\
\text { significância às mudanças no preço do } \\
\text { petróleo. }\end{array}$ \\
\hline $\begin{array}{l}\text { Maysami e Koh (2000) } \\
\text { Singapura } \\
(1988-1995)\end{array}$ & $\begin{array}{l}\text { 1. Taxa de Juros; } 2 . \text { M2; } 3 . \\
\text { IPC; } 4 \text {. IPI; } 5 \text {. Taxa de juros } \\
\text { interbancário; entre outros }\end{array}$ & VEC & $\begin{array}{l}\text { Os retornos das ações apresentaram uma } \\
\text { resposta negativa às mudanças nas taxas } \\
\text { de juros e positiva às alterações na taxa de } \\
\text { câmbio; os fundamentos macroeconômicos } \\
\text { dos EUA e do Japão afetam o preço das ações. }\end{array}$ \\
\hline $\begin{array}{l}\text { Perales e Robins }(2002) \\
\text { México } \\
(1990-2000)\end{array}$ & $\begin{array}{l}\text { 1. IPC; 2. Produção industrial; } \\
\text { 3. M1; 4. Taxa de desemprego; } \\
\text { 5. Taxa de juros; } 6 \text {. Taxa de } \\
\text { câmbio; } 7 \text {. Índice Dow Jones; } \\
\text { 8. Taxa de juros dos títulos do } \\
\text { tesouro norte americano; }\end{array}$ & $\begin{array}{l}\text { VAR e } \\
\text { Causalidade de } \\
\text { Granger }\end{array}$ & $\begin{array}{l}\text { Há uma grande influência do ciclo econômico } \\
\text { norte americano no mercado financeiro } \\
\text { mexicano. }\end{array}$ \\
\hline
\end{tabular}




\begin{tabular}{|c|c|c|c|}
\hline $\begin{array}{l}\text { Autores (ano), } \\
\text { País e Periodo }\end{array}$ & Variáveis & Método & Resultado \\
\hline $\begin{array}{l}\text { Gan, Lee, Yong, Zhang } \\
\text { (2006) } \\
\text { Nova Zelândia } \\
(1990-2003)\end{array}$ & $\begin{array}{l}\text { 1. Produção industrial; 2. IPC; } 3 \text {. } \\
\text { Taxa de Juros de curto e longo } \\
\text { prazo; } 4 \text {. Taxa de câmbio; } 5 \text {. M1; } \\
\text { 6. Preço do barril do petróleo; }\end{array}$ & $\begin{array}{l}\text { VEC e } \\
\text { Causalidade de } \\
\text { Granger }\end{array}$ & $\begin{array}{c}\text { O índice de ações neozelandês é influenciado } \\
\text { negativamente pela inflação com defasagem } \\
\text { de quatro meses e positivamente pela } \\
\text { produção industrial. }\end{array}$ \\
\hline $\begin{array}{l}\text { Pimenta Junior e Higuchi } \\
\text { (2008) } \\
\text { Brasil } \\
(1994-2005)\end{array}$ & $\begin{array}{c}\text { 1. Taxa de juros; } 2 \text {. Inflação; } 3 . \\
\text { Taxa de câmbio; }\end{array}$ & $\begin{array}{l}\text { VAR e } \\
\text { Causalidade de } \\
\text { Granger; }\end{array}$ & $\begin{array}{c}\text { Nenhuma das variáveis macroeconômicas } \\
\text { selecionadas apresentou uma relação de } \\
\text { causalidade estatisticamente significativa em } \\
\text { relação ao Ibovespa. }\end{array}$ \\
\hline $\begin{array}{l}\text { Singh }(2010) \\
\text { Índia } \\
(1995-2009)\end{array}$ & $\begin{array}{l}\text { 1. Produção industrial; } 2 \text {. } \\
\text { Inflação; } 3 \text {. Taxa de câmbio; }\end{array}$ & $\begin{array}{l}\text { Causalidade } \\
\text { de Granger e } \\
\text { correlação; }\end{array}$ & $\begin{array}{c}\text { Todos os indicadores possuem correlações } \\
\text { positivas altas, excetuando a taxa de câmbio; } \\
\text { O índice de ações causa variações na atividade } \\
\text { industrial e na inflação, somente a atividade } \\
\text { industrial causa o índice. }\end{array}$ \\
\hline Ameer (2012) & $\begin{array}{l}\text { 1. Taxa de juros; 2. Produção } \\
\text { Industrial; }\end{array}$ & GARCH & $\begin{array}{c}\text { Há uma relação de causalidade entre as } \\
\text { variáveis macroeconômicas e a oferta inicial } \\
\text { de ações (IPO) e esta relação é mais intensa } \\
\text { em períodos de baixo crescimento econômico; } \\
\text { aumento nas taxas de juros causa efeito } \\
\text { negativo sobre IPO. }\end{array}$ \\
\hline $\begin{array}{l}\text { Oliveira e Franscaroli (2014) } \\
\text { Brasil } \\
(1998-2012)\end{array}$ & $\begin{array}{l}\text { 1. Taxa de juros; 2. Produção } \\
\text { Industrial; 3. Inflação; }\end{array}$ & $\begin{array}{l}\text { VAR e } \\
\text { Causalidade de } \\
\text { Granger; }\end{array}$ & $\begin{array}{l}\text { A maior parte dos desvios causados na } \\
\text { variância da IPO é explicada por ela mesma } \\
\text { (cerca de } 90 \% \text { em } 10 \text { anos), seguida da taxa } \\
\text { de juros e da inflação; Por meio do teste de } \\
\text { Causalidade de Granger observaram que todas } \\
\text { as variáveis afetam em nível a emissão de IPO. }\end{array}$ \\
\hline $\begin{array}{l}\text { Machado, Gartner e } \\
\text { Machado (2017) Brasil } \\
\text { (1999-2017) }\end{array}$ & $\begin{array}{l}\text { 1.Ibovespa; 2.Inflação; } 3 . \text { Taxa } \\
\text { de juros; 4.M1; 5.PIB; } 6 \text {. } \\
\text { Importações; 7. Exportações; } \\
\text { 8.Taxa de câmbio }\end{array}$ & $\begin{array}{l}\text { Markov- } \\
\text { Switching }\end{array}$ & $\begin{array}{l}\text { As variáveis oferta de moeda, atividade } \\
\text { econômica, nível de importação e exportação } \\
\text { impactam negativamente o retorno de } \\
\text { mercado, enquanto que as taxas de juros e } \\
\text { de câmbio apresentaram um relacionamento } \\
\text { positivo com este retorno. }\end{array}$ \\
\hline $\begin{array}{c}\text { Bernardelli e Castro (2020) } \\
\text { Brasil (2003-2019) }\end{array}$ & $\begin{array}{l}\text { 1.Ibovespa; 2.Taxa de juros; } \\
\text { 3.Receita do governo; 4.PIB; } 5 \text {. } \\
\text { Necessidade de financiamento } \\
\text { do setor público; 7. Dow Jones; } \\
\text { 8.Taxa de câmbio }\end{array}$ & GLS & $\begin{array}{c}\text { Os resultados mostram que as variáveis } \\
\text { macroeconômicas continuam exercendo } \\
\text { influência sobre o Ibovespa, conforme } \\
\text { preconiza a literatura, exceto, a proxy para a } \\
\text { variável de estabilidade financeira do governo } \\
\text { central. }\end{array}$ \\
\hline
\end{tabular}

Fonte: elaborado pelos autores (2020).

Ressalta-se que dentre os trabalhos revisados, independente do país de origem, a proxy para o mercado de capitais é um índice amplo de mercado ou o índice Ibovespa, exceto Ameer (2011) e Oliveira e Franscaroli (2014) que utilizaram a oferta pública inicial de ações.

De forma geral, Vetores Autorregressivos (VAR), Causalidade de Granger e Vetor de Correção de Erros (VEC) são os procedimentos metodológicos predominantemente utilizados nos estudos que relacionam o comportamento do mercado de capitais e as variáveis macroeconômicas (Quadro 1). Pode-se observar ainda que são utilizadas as mais diversas variáveis macroeconômicas. Entretanto, independente do modelo adotado, as variáveis utilizadas possuem certa convergência, pois na maioria dos casos são utilizadas taxa de juros, taxa de câmbio, inflação, meios de pagamento e produção industrial.

Quanto aos resultados apresentados, todos os trabalhos evidenciaram alguma relação entre as variáveis macroeconômicas utilizadas e o mercado de capitais, exceto Pimenta Junior e Higuchi (2008), em que taxa de juros, inflação e taxa de câmbio não apresentaram relação de causalidade estatisticamente significativa em relação ao índice de ações considerado (Ibovespa). Excluindo este trabalho específico, de maneira geral, as proxies para o mercado de capitais possui uma relação negativa com a inflação e taxa de juros e uma relação positiva com a taxa de câmbio e atividade industrial.

Cabe ressaltar ainda que trabalhos como de Perales e Robins (2002) e Maysami e Koh (2000) evidenciam a influencia da atividade econômica de um país sobre o mercado de capitais de outro país. Nestes casos específicos, enquanto Perales e Robins (2002) concluem que o ciclo econômico norte americano afeta o mercado financeiro mexicano, Maysami e Koh (2000) afirmam que os fundamentos macroeconômicos dos Estados Unidos e do Japão afetam o preço das ações no mercado acionário de Singapura. 
Portanto, pode-se concluir que dentre os trabalhos analisados, de forma majoritária e independente da metodologia utilizada, as variáveis macroeconômicas selecionadas possuem alguma relação com o mercado de capitais.

\section{PROCEDIMENTOS METODOLÓGICOS}

Em conformidade com o objetivo deste estudo, o método de pesquisa utilizado é o quantitativo, por utilizar um modelo de séries temporais com Vetores de Correção de Erros (VEC). O modelo empírico, os testes de validação deste modelo, as variáveis e a base de dados são apresentados a seguir.

\subsection{Modelo empírico}

Os principais modelos para mensurar o impacto das variáveis macroeconômicas no índice Ibovespa são de Vetores Auto-Regressivos (VAR) e de Vetores de Correção de Erros (VEC) (Darrat \& Mukherjee, 1986; Mukherjee \& Naka, 1995; Gjerde \& Saettem 1999; Maysami \& Koh, 2000; Perales \& Robins, 2002; Gan, et al., 2006; Pimenta Junior \& Higuchi, 2008; Oliveira \& Franscaroli, 2014).

Nesse sentido, Enders (2014) pontua que quando uma variável é endógena, uma extensão natural da análise da função de transferência é tratar cada variável simetricamente pelo sistema dos VAR. Alguns pressupostos estabelecidos por Enders (2014), é que as variáveis devem ser estacionárias e que os erros sejam homocedásticos e não correlacionados.

Para verificar se uma série temporal é estacionária, faz-se necessário recorrer ao conceito de Raiz Unitária: se uma das séries apresenta raiz unitária, qualquer choque exógeno sofrido gera efeito permanente, as flutuações indicariam comportamentos não-transitórios e a trajetória de cada variável pode não convergir no longo prazo (Fonseca, Paixao \& Maia, 2008). Nesse sentido, existem diversos testes que possibilitam determinar se uma série contém ou não raiz unitária, entre os quais destacam-se os testes de Dickey-Fuller (DF), Dickey-Fuller Aumentado (ADF), Phillips-Perron (PP) e o Denis Kwiatkowski, Peter C. B. Phillips, Peter Schmidt e Yongcheol Shin (KPSS) os quais foram apresentados na Anexo 1 (Fonseca et al., 2008).

Após os testes de raiz unitária (ADF, PP e KPSS), é necessário verificar a existência de equilíbrio ou relacionamento de longo prazo entre as variáveis econômicas por meio dos testes de cointegração, que utilizam os critérios de traço e de máximo autovalor. O resultado do teste de cointegração permite avaliar qual método é mais robusto para estimação, caso as variáveis não forem cointegradas o recomendado é utilizar o modelo vector auto regression (VAR), caso contrário, o método vector erro correction (VEC) é mais robusto (Dickey, Jansen \& Thornton, 2007).

Nesse sentido, como será mostrado a seguir, os testes apontam que as variáveis se coitegraram, logo os resultados foram estimados aplicando o VEC. Além disso, outra importante constatação na formulação do modelo é a definição do número de defasagens a serem incluídas no modelo (Fonseca et al., 2008). Para determinar a ordem de defasagens, utilizou-se os critérios de Akaike (Akaike's Information Criteria - AIC) e Schwartz (Schwartz's Bayesian Information Criteria - SBC). De forma complementar, testes de robustez dos resíduos foram aplicados, como o teste de autocorrelação residual (Multiplicador de Lagrange) e heterocedasticidade (White).

Com o objetivo de verificar se há causalidade entre as variáveis selecionadas, aplicou-se o teste de causalidade proposto por Granger (1969), que testa a causalidade temporal entre duas variáveis, ou seja, se uma variável defasada ajuda a prever o comportamento de outra variável. Contudo, de acordo com Gujarati (2011), por mais forte que uma relação estatística seja, a questão de causalidade é controversa, sendo recomendável surgir de fundamentos teóricos e não fundamentalmente estatísticos. Nesse sentido, esse trabalho testa a causalidade entre as variáveis econômicas baseado nas diversas pesquisas supracitadas nas seções anteriores, que aplicam os mesmos procedimentos metodológicos, sendo um método usual na análise desta temática. Assim, a próxima seção apresenta a base de dados utilizada neste trabalho. O pacote estatístico utilizado para realizar as estimativas foi o EViews 8.

\subsection{Base de dados}

A base de dados utilizada neste estudo é do tipo séries temporais com periodicidade mensal e compreende o período de janeiro de 2000 a fevereiro de 2019, perfazendo um total de 230 observações. A escolha do período se pautou na tentativa de minimizar a dispersão dos dados selecionados, pois o período em questão, além de apresentar relativa estabilidade das variáveis econômicas, exclui os ajustes adversos ocorridos na economia brasileira decorrentes dos primeiros anos de implementação do Plano Real.

É importante ressaltar que, embora algumas variáveis estejam disponíveis em periodicidade diária, tal como o Câmbio e a Selic, a maioria das variáveis econômicas são encontradas apenas com variabilidade mensal. Além disso, as séries são disponibilizadas mensalmente, sendo que, nenhum procedimento estatístico é aplicado neste presente estudo para a conversão da periodicidade das séries ${ }^{2}$. Tal informação pode ser confirmada por meio do dados contidos no Banco Central do Brasil - BACEN (2019) e no Instituto de Pesquisa Econômica Aplicada - IPEADATA (2019), verificados a partir dos códigos disponibilizados na Quadro 2. Assim, o Quadro 2 apresenta as variáveis utilizadas no modelo deste

2 Exceto a variável do índice ibovespa, ela foi construída com base na média de todos os valores diários do mês. 
estudo, as quais foram definidas a partir da revisão da literatura (seção 2), das análises de correlação e as especificações econométricas testadas.

Quadro 2 - Variáveis utilizadas no modelo

\begin{tabular}{|c|c|c|}
\hline Variável & Descrição & Fonte \\
Ibovespa & Índice ibovespa & IPEA (2019) \\
Câmbio & Índice da taxa de câmbio real efetiva & BACEN (2019) \\
PIB & PIB mensal & BACEN (2019) \\
Reserva & Reservas internacionais & IPEA (2019) \\
Selic & Taxa de juros & BACEN (2019) \\
\hline
\end{tabular}

Fonte: elaborado pelos autores (2020).

Nota: maiores informações sobre as proxys utilizadas são apresentadas no Anexo 3

A variável "Ibovespa" é o principal índice do mercado de ações. Foi criado em 1968 e, ao longo desses 50 anos, consolidou-se como referência para investidores ao redor do mundo. É o mais importante indicador de desempenho médio dos ativos mais negociados e representativos do mercado de ações do Brasil (Bmfbovespa, 2019).

De acordo com Brondani, Baggio, Agudo e Sanjuán (2013) o Ibovespa tem a finalidade de servir como indicador médio do comportamento do mercado acionário. Dessa forma, sua composição procura aproximar-se o mais possível da real configuração das negociações à vista.

A variável "Câmbio" representa a taxa de conversão entre o real e o dólar americano. De acordo com Bernardelli et al. (2017), uma desvalorização cambial impacta negativamente no valor das ações, porque os investimentos internacionais representam uma grande proporção do recurso aplicado nas empresas de capital aberto. Dessa forma, um aumento da taxa de câmbio pode inibir tal ação, pois além dos rendimentos normais, um investimento advindo de outros países exige uma consideração acerca do câmbio.

Já a variável "PIB", representa o Produto Interno Bruto do Brasil, corrigido para valores reais pelo Índice de Preços ao Consumidor Amplo (IPCA). Para Bernardelli e Bernardelli (2016), o valor esperado para essa variável é positivo, em virtude que uma elevação na atividade econômica do país, aumenta a demanda de bens e serviços das empresas de capital aberto e, consequentemente, ocorre uma elevação no valor de mercado delas.

A variável "Reserva", representa as reservas internacionais mensais em milhões. A importância dessa variável decorre de a mesma ser uma proxy da confiabilidade do país. Em outras palavras, quanto maior for a reserva internacional de um país, maior segurança ele terá às oscilações do mercado internacional, ou seja, acumulação de reservas intemacionais pode ser vista como uma auto-proteção para a saída súbitas de recursos do país (Feldstein, 1999; Meurer, 2006). Assim, o impacto esperado dessa variável é positivo.

De acordo com o IPEADATA (2019), a taxa de juros Selic Over "Selic", é a taxa média mensal ponderada e ajustada das operações de financiamento por um dia, lastreadas em títulos públicos federais e cursadas no referido sistema na forma de operações compromissadas. Para Bernardelli e Bernardelli (2016), espera-se que o sinal dessa variável seja negativo, em virtude de que ao se investir em títulos atrelados à taxa Selic há um custo de oportunidade ao agente superavitário.

A variável "Confiança” reflete o Índice de Confiança do Consumidor, elaborado pela Fecomercio e disponibilizado pelo Bacen (2019). De acordo com Bernardelli, Bernardelli e Castro (2017), o valor esperado dessa variável é positivo, em virtude de que à medida que os consumidores possuem uma melhor expectativa do desempenho econômico, eleva-se o consumo e o resultado das empresas.

Logo, a fim de verificar o impacto das variáveis macroeconômicas no índice Ibovespa a seção seguinte tratará as análises dos resultados econométricos, bem como, os testes de robustez e as discussões.

\section{ANÁLISE DOS RESULTADOS E TESTES DE ROBUSTEZ}

O primeiro passo para análise econométrica é realizar uma análise gráfica do comportamento da série. Dessa forma, a Figura 1 apresenta o comportamento das variáveis apresentadas no Quadro 2. 
Figura 1 - Comportamento das variáveis ao longo do tempo
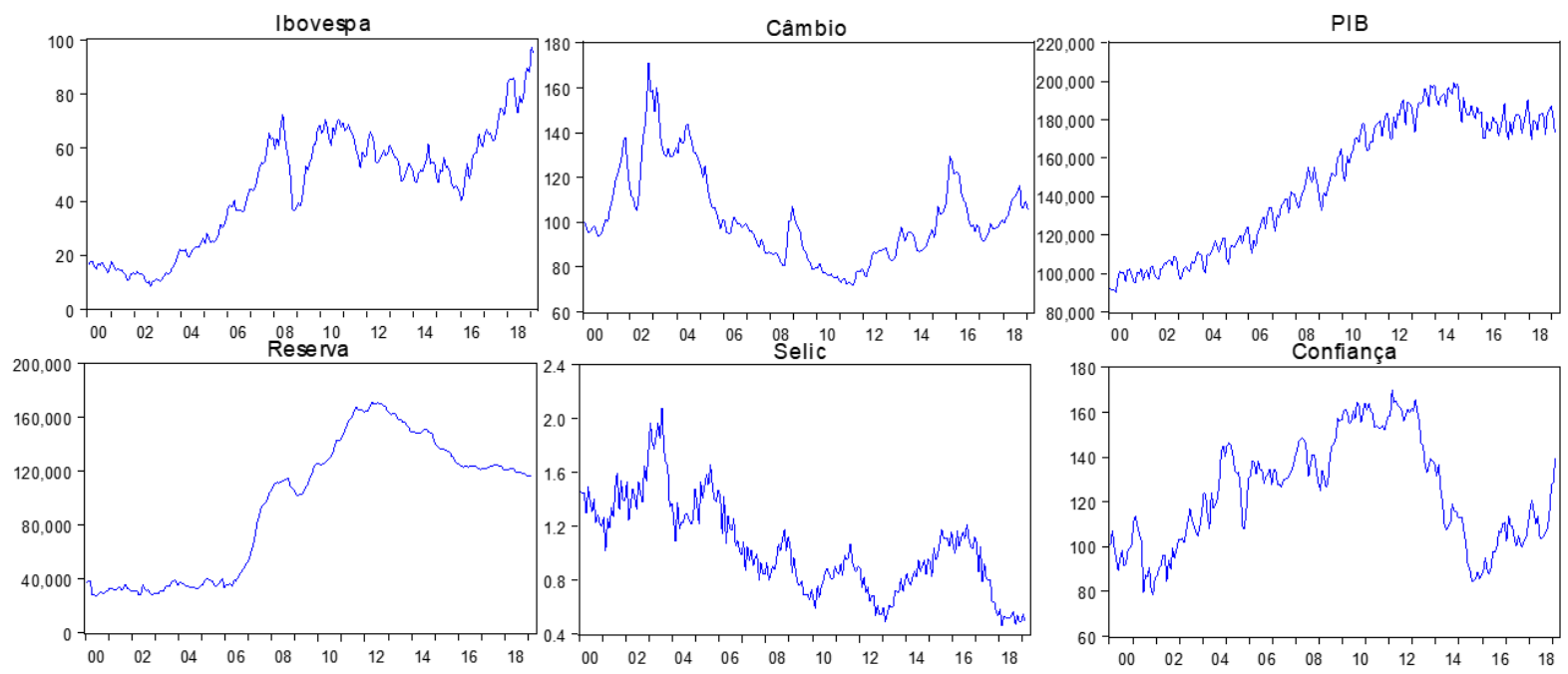

Fonte: Elaborado pelos autores (2020).

Os resultados apresentados na Figura 1 mostram o comportamento das variáveis macroeconômicas e do mercado acionário de 2000 a 2019. É possível visualizar uma série de fatores, como a crescente tendência de alta da bolsa de valores no Brasil, acompanhada pelo aumento do Produto Interno Bruto (PIB). Esse resultado sinaliza que o mercado acionário no Brasil vem se aprimorando e se consolidando como uma alternativa de investimento viável aos investidores nacionais e internacionais. Outra tendência importante que pode ser visualizada é o aumento das reservas internacionais no Brasil, principalmente entre o período de 2006 a 2013. Além disso, a constante queda da taxa básica de juros Selic, atingindo os menores patamares da história no final do segundo semestre de 2018. Para aprofundar esta análise inicial, a Tabela 1 apresenta a média, o desvio-padrão, valores máximos e mínimos das variáveis utilizadas.

Tabela 1 - Estatísticas descritivas da série

\begin{tabular}{c|c|c|c|c|c|c}
\hline & Ibovespa & Câmbio & Pib & Reserva & Selic & Confiança \\
\hline Média & 45,49 & 102,05 & $\mathrm{R} \$ 148,127$ & $\mathrm{R} \$ 95,979$ & 1,04 & 123,70 \\
Desvio-padrão & 21,78 & 19,96 & $\mathrm{R} \$ 34,580$ & $\mathrm{R} \$ 50,423$ & 0,34 & 24,08 \\
Máximo & 97,39 & 171,03 & $\mathrm{R} \$ 199,275$ & $\mathrm{R} \$ 171,465$ & 2,08 & 170,18 \\
Mínimo & 8,62 & 71,76 & $\mathrm{R} \$ 90,118$ & $\mathrm{R} \$ 27,809$ & 0,47 & 78,31 \\
\hline Observações & 230 & 230 & 230 & 230 & 230 & 230 \\
\hline
\end{tabular}

Fonte: Elaborado pelos autores (2020).

Nota: a fim de facilitar a intertretação, os valores se encontram em forma não logarítima.

Os dados da Tabela 1 fornecem informações adicionais sobre as séries utilizadas. Em relação ao índice Ibovespa, é possível visualizar que o valor médio é muito inferior ao valor máximo da série, registrado em fevereiro de 2019, que retrata uma elevação dos preços das ações das empresas listadas na bolsa de valores. A desaceleração das economias mundiais e a queda na taxa básica de juros (Selic) foram um dos fatores que tornaram o mercado de ações brasileiro mais atraente. Além disso, o valor máximo da taxa de câmbio também foi encontrado nos últimos períodos da série (Agosto de 2018), esse aumento da depreciação do câmbio se deve em partes pela incerteza políticas em relação as eleições brasileiras. Outro exemplo mais recente foi a incerteza no mercado internacional em relação ao acordo comercial entre EUA e a China, essas depreciações evidenciam uma possível relação inversa entre o índice do mercado de ações e a taxa de câmbio. No que diz respeito à atividade econômica, embora a série apresente uma tendência de alta, o valor máximo é de outubro de 2014, dado que o Brasil experimentou sucessivos períodos de recessão a partir de 2015. Da mesma forma que a atividade econômica, as reservas internacionais reduziram substancialmente desde o início da crise econômica, tendo o valor máximo registrado em abril de 2012, a queda nas reservas é justificada em grande medida pelos contratos de swaps cambiais que o Bacen ofereceu ao mercado na tentativa de minimar os efeitos negativos sobre a economia brasileira de um aumento abrupto na taxa de câmbio. Já em relação à taxa de juros Selic, o menor valor é de Fevereiro de 2018, mostrando a contínua redução da taxa básica de juros. Por fim, os maiores níveis de confiança foram identificados também em Fevereiro de 2012. 
Além das tendências das séries, é importante verificar se as séries são estacionárias, ou seja, se elas se desenvolvem no tempo de modo que a escolha da origem do período não seja importante (Morettin \& Toloi, 2006). Conforme pode ser observado no Anexo 1, todas as variáveis foram identificadas, por meio do teste de raiz unitária, como não estacionárias em nível, sendo recomendável diferencia-lás a fim de que se tornem estacionárias (BUENO, 2011). As séries em primeira diferença são estacionárias (Anexo 1).

Os testes de cointegração permitem verificar a existência de equilíbrio ou relacionamento de longo prazo entre as variáveis econômicas. Dessa forma, a Tabela 2 apresenta os testes de cointetração Traço e Máximo-autovalor.

Tabela 2 - Teste de cointegração de Johasen (13 Defasagens)

\begin{tabular}{c|c|c|c|c}
\hline $\begin{array}{c}\text { No de eq. } \\
\text { Cointegradas }\end{array}$ & Estatística Traço & VC - 1\% & $\begin{array}{c}\text { Estatística Máximo- } \\
\text { Autovalor }\end{array}$ & VC - 5\% \\
\hline Nenhuma & 138.303 & 104.961 & 59.927 & 45.869 \\
Ao menos 1 & 78.375 & 77.818 & 34.871 & 39.370 \\
Ao menos 2 & 43.504 & 54.681 & 21.068 & 32.715 \\
Ao menos 3 & 22.435 & 35.458 & 13.194 & 25.861 \\
Ao menos 4 & 9.241 & 19.937 & 6.684 & 18.520 \\
Ao menos 5 & 2.557 & 6.6348 & 2.557 & 6.6348 \\
\hline
\end{tabular}

Fonte: Elaborado pelos autores (2020).

Nota: quando o valor da estatística é superior ao valor crítico (VC), rejeita-se a hipótese nula - a um nível de confiança de $99 \%$ - de ausência de cointegração.

A Tabela 2 indica a existência de ao menos 1 equação cointegrada pelos critérios de traço e de máximo autovalor, a um nível de confiança de $99 \%$. Nesse caso, as relações de cointegração entre as variáveis tornam o sistema de equações mais estável, de forma que o sistema estimado é estacionário e um conjunto de possíveis direções, tornando possível a estimação do modelo VEC (Dickey et al., 2007). De forma sequencial, é necessário identificar o número de defasagens das variáveis a serem incluídas no modelo e, para tanto, foram realizados os testes de seleção do número de defasagens do sistema (Tabela 4).

Tabela 4 - Seleção de defasagens

\begin{tabular}{|c|c|c|c|c|c|c|}
\hline Lag & LogL & LR & FPE & AIC & SC & HQ \\
\hline 0 & -636.963 & NA & $1.59 \mathrm{E}-05$ & 5.981048 & 6.075113 & 6.019055 \\
\hline 1 & 1100.786 & 3362.341 & $2.13 \mathrm{E}-12$ & -9.84917 & $-9.190719 *$ & -9.58313 \\
\hline 2 & 1187.957 & 163.8001 & $1.32 \mathrm{E}-12$ & -10.3252 & -9.10234 & $-9.831095^{*}$ \\
\hline 3 & 1239.966 & 94.82609 & $1.14 \mathrm{E}-12$ & -10.4741 & -8.68688 & -9.75198 \\
\hline 4 & 1292.75 & 93.29373 & $9.80 \mathrm{E}-13$ & -10.6302 & -8.27863 & -9.68008 \\
\hline 5 & 1342.049 & 84.38118 & $8.71 \mathrm{E}-13$ & -10.754 & -7.83795 & -9.57575 \\
\hline 6 & 1382.98 & 67.77403 & 8.39E-13 & -10.7998 & -7.31944 & -9.39358 \\
\hline 7 & 1437.02 & 86.46392 & $7.18 \mathrm{E}-13$ & -10.9676 & -6.92286 & -9.33336 \\
\hline 8 & 1465.899 & 44.59395 & $7.80 \mathrm{E}-13$ & -10.9014 & -6.29223 & -9.03907 \\
\hline 9 & 1524.549 & 87.29361 & $6.45 \mathrm{E}-13$ & -11.1121 & -5.93855 & -9.02174 \\
\hline 10 & 1561.564 & 53.02674 & $6.56 \mathrm{E}-13$ & -11.1215 & -5.38361 & -8.80314 \\
\hline 11 & 1632.318 & 97.40939 & $4.90 \mathrm{E}-13$ & -11.4448 & -5.14251 & -8.89839 \\
\hline 12 & 1696.863 & 85.26002 & $3.91 \mathrm{E}-13$ & -11.7104 & -4.84366 & -8.9359 \\
\hline 13 & 1742.137 & 57.2767 & $3.77 \mathrm{e}-13^{\star}$ & -11.7966 & -4.36554 & -8.79413 \\
\hline
\end{tabular}




\begin{tabular}{c|c|c|c|c|c|c}
\hline Lag & LogL & LR & FPE & AIC & SC & HQ \\
\hline 14 & 1768.306 & 31.6458 & $4.37 \mathrm{E}-13$ & -11.7052 & -3.7097 & -8.47463 \\
15 & 1822.761 & $62.81323^{*}$ & $3.94 \mathrm{E}-13$ & $-11.87685^{\star}$ & -3.31699 & -8.41827 \\
\hline
\end{tabular}

Fonte: Elaborado pelos autores (2020).

Nota: ${ }^{*}$ ) indica o número de defasagens selecionado por cada critério. LR: estatística LR; FPE: erro final de previsão; AIC: critério de informação Akaike; SC: critério de informação Schwarz; HQ: critério de informação de Hannan-Quinn.

A Tabela 4 mostra que os critérios LR e AIC sugerem a inclusão de 15 defasagens ao modelo, já os critérios SC e HQ, sugerem, respectivamente, 1 e 2 defasagens. As estimativas do VEC com 15 defasagens resultaram em modelos cujos os resíduos não foram autocorrelacionados e homocedásticos, diferentemente dos modelos com menos defasagem, de acordo com o teste de Multiplicador de Lagrange e de heterocedasticidade (White). Portanto, optou-se pela utilização de 15 defasagens. As análises apresentadas a seguir estão organizadas em torno de três principais hipóteses (i) as variáveis macroeconômicas causam a variação do índice Ibovespa; (ii) as variáveis macroeconômicas explicam a variação do valor do índice Ibovespa e (iii) o comportamento do índice Ibovespa é relevante na análise das variáveis macroeconômicas. Inicialmente, a Tabela 5 apresenta o teste de causalidade de Granger.

Tabela 5 - Teste de Causalidade de Granger

\begin{tabular}{|c|c|c|c|}
\hline Hipótese nula & Prob. & Hipótese nula & Prob. \\
\hline $\begin{array}{c}\text { A Confiança não causa o } \\
\text { Ibovespa }\end{array}$ & 0.0719 & $\begin{array}{c}\text { O Ibovespa não causa a } \\
\text { Confiança }\end{array}$ & 0.5308 \\
\hline $\begin{array}{l}\text { O Câmbio não causa o } \\
\text { Ibovespa }\end{array}$ & 0.6499 & $\begin{array}{c}\text { O Ibovespa não causa o } \\
\text { Câmbio }\end{array}$ & 0.0000 \\
\hline O PIB não causa o Ibovespa & 0.3725 & O Ibovespa não causa o PIB & 0.0519 \\
\hline $\begin{array}{c}\text { A Reserva não causa o } \\
\text { Ibovespa }\end{array}$ & 0.207 & $\begin{array}{c}\text { O Ibovespa não causa a } \\
\text { Reserva }\end{array}$ & 0.0085 \\
\hline A Selic não causa o Ibovespa & 0.0978 & O Ibovespa não causa a Selic & 0.7068 \\
\hline
\end{tabular}

Fonte: elaborado pelos autores (2020).

Nota: as variáveis foram transformadas em primeira diferença, uma vez que o teste de causalidade de Granger exige que as séries sejam estacionárias.

A Tabela 5 apresenta o resultado do teste de causalidade de Granger para as variáveis selecionadas. Os resultados mostram que apenas duas variáveis parecem ter uma relação de causa com o índice Ibovespa: a taxa Selic, significativo a 10\%, (o qual funciona como um mecanismo de trade-off no mercado acionário) e a confiança (expectativa dos agentes), significativo também a $10 \%$. As variáveis Câmbio, PIB e Reserva parecem não exercer o mesmo efeito. Esse resultado é importante do ponto de vista teórico, uma vez que sinaliza ao investidores que, ao tentar prever o comportamento do Índice Ibovespa, uma atenção maior deve ser designada para a confiança dos agentes e a taxa de juros Selic. Por outro lado, o Ibovespa parece causar no sentido de Granger três variáveis econômicas: PIB, Câmbio e Reserva, mostrando que se trata de uma importante variável no contexto macroeconômico. De forma sequencial, ao se identificar essas relações causais e considerando que o modelo encontra-se com uma especificação adequada, o próximo passo é a avaliação das funções impulso resposta. Assim, a Figura 2 apresenta as funções de resposta a impulso acumuladas no índice Ibovespa.

Na Figura 2 o PIB apresenta baixa relação sobre o Ibovespa, resultado inesperado do ponto de vista teórico e diverge de outros resultados empíricos para o Brasil (Bernardelli \& Bernardelli, 2016; Bernardelli et al., 2017; Bernardelli \& Castro, 2020). Esse resultado pode ser fruto de uma mudança de comportamento do mercado visualizada nos últimos períodos da série, ou seja, embora o Brasil tenha apresentado baixos índices de crescimento econômico, o Ibovespa elevou-se significativamente. É importante ressaltar que a pesquisa de Machado Gartner e Machado (2017) apontou relação negativa entre o PIB e o retorno do mercado de ações. Já em relação a taxa Selic, o resultado encontrado está de acordo com a literatura e com os resultados empíricos apresentados por (Bernardelli \& Bernardelli, 2016; Bernardelli et al., 2017, Oliveira \& Franscaroli, 2014; Bernardelli \& Castro, 2020). No que diz respeito a introdução das variáveis reservas internacionas e o índice de confiança e seus efeitos sobre o mercado de capitais, percebe-se que o impacto das reservas também está de acordo com o valor esperado, uma vez que a elevação das reservas internacionais tende a dar maior segurança aos investidores sobre a capacidade de solvênia do país. No que tange a variável de Confiança, assim como os resultados obtidos por Bernardelli et al. (2017), porém, com uma outra abordagem econométrica, o impacto dessa variável é positivo e se mostra relevante a sua análise no atual contexto macroeconômico. 
Figura 2 - Funções de resposta a impulso nas variáveis macroeconômicas Respsta a um desvio-padrão
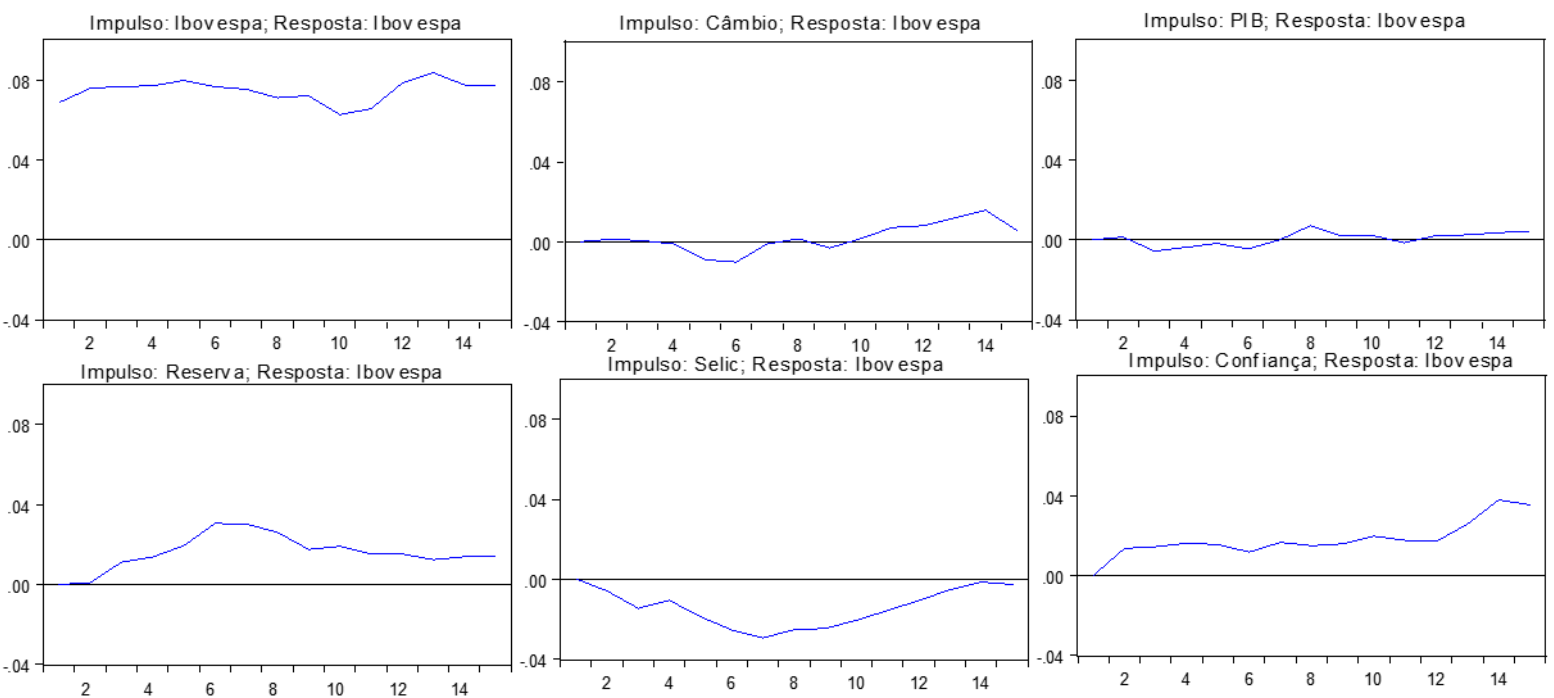

Fonte: Elaborado pelos autores (2020).

A variável câmbio apresentou um comportamento negativo nos períodos iniciais, mas que se torna positivo nos períodos seguintes. No entanto, dado o comportamento da série, as estimativas mostram que essa relação parece não ser significativa no longo prazo. Um indicativo adicional dessa relação são os resultados do teste de Causalidade de Granger, que mostram que não existe uma relação de causalidade entre a variável Câmbio e o Ibovespa, mostrando que essa relação parece não ser significativa.

Embora tenha se observado relevância das variáveis macroeconômicas para explicar o movimento ocorrido no mercado acionário, os valores encontrados nas estimativas são pequenos e algumas variáveis macroeconômicas podem não exercer impacto sobre o índice Ibovespa, uma vez que o intervalo 0 (zero) é um resultado possível. No entanto, complementarmente, faz-se necessário observar como o Ibovespa afeta as variáveis Macroeconômicas. Para isso, a Figura 3 apresenta as Funções de Resposta a impulso da variável Ibovespa.

A análise da Figura 3 indica que o Ibovespa possui forte relação com as variáveis macroeconômicas, uma vez que os choques tendem a se perpetuar e não retornam aos patamares iniciais, principalmente no que diz respeito ao câmbio e às reservas. A relação encontrada nesse impulso na variável Ibovespa estabelece uma questão relevante, que as variáveis macroeconômicas podem estar intimamente ligadas ao comportamento do mercado acionário, tornando-a elegível a ser elencada como uma variável explicativa para o crescimento econômico dos países. Em conformidade com a teoria econômica, estes resultados corroboram com os estudos de Grôppo, (2004); Grôppo, (2005); Oliveira, (2006); Pimenta Junior e Higuchi (2008), Oliveria e Frascaroli, (2014); Bernardelli e Bernardelli, (2016); Da Silva Ribeiro, Leite e Justo (2016); Bernardelli, Bernardelli e Castro, (2017), Machado, Gartner e Machado (2017) e Bernardelli e Castro (2020) que asseveram que o mercado de capitais é um importante intermediador de recursos para a economia. 
Figura 3 - Funções de resposta a impulso no Ibovespa
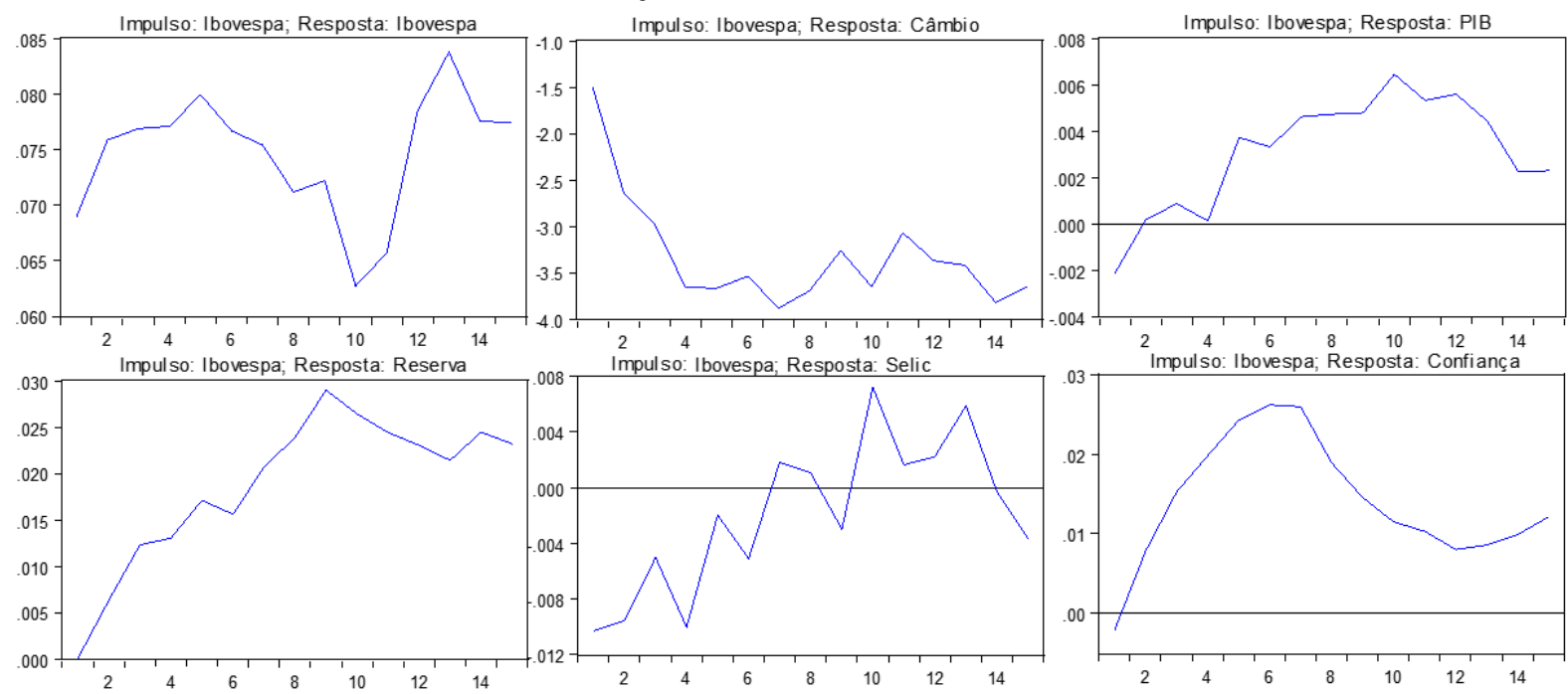

Fonte: elaborado pelos autores (2020)

Além disso, ao comparar as Figuras 2 e 3, nota-se que o Ibovespa responde melhor ao papel de variável explicativa do que ao de variável explicada. Isso pode ocorrer devido as grandes oscilações que ocorrem no mercado acionário, que em algumas vezes refletem mais um movimento especulativo do que uma oscilação macroeconômica. Nesses casos, a adoção de modelos univariados, com oscilações diárias, podem captar com maior precisão o movimento do mercado acionário.

Assim, respondendo a terceira hipótese do objetivo de pesquisa, o comportamento das empresas listadas no Ibovespa é relevante na análise das variáveis macroeconômicas, principalmente sobre o PIB, câmbio e sobre as reservas internacionais. Outro resultado que merece destaque é que a introdução das variáveis índice de confiança e reservas internacionais, mostram-se importantes nas análises sobre as variáveis macroeconômicas e o mercado acionário brasileiro.

É importante mencionar que a série do Ibovespa alterou-se significativamente ao longo do período do estudo, conforme pode ser visualizado na Figura 1. Em outras palavras, de 2000 a 2019, houve inúmeros acontecimentos macroeconômicos que proporcionaram uma mudança no comportamento da série, por exemplo, a crise de confiança iniciada pela eleição de Luiz Inácio Lula da Silva, a Crise Financeira de 2008, a desvalorização do real a partir de 2013, a recessão econômica iniciada em 2014, as crises políticas iniciadas a partir de 2015, entre outros desequilíbrios. Com o objetivo de verificar as mudanças no comportamento da série, verificou-se a existência de quebras estruturais. As quebras estruturais na série foram identificadas em Outubro de 2009 e Julho de 2016, por meio do supremum Wald test que identifica quebras estruturais desconhecidas na série e considera todas as possibilidades de quebras (Wright, 1998).

Para controlar os efeitos das quebras estruturais nas estimativas, foram criadas variáveis binárias que representavam três períodos (2000-2009; 2009-2016 e 2016-2019). De forma sequencial, incluiu-se duas binárias nas estimativas (2009-2016 e 2016-2019) a fim de controlar os períodos de quebras das estimativas. Os Anexos 2 e 3 mostram os resultados das funções impulso-resposta para estas duas variáveis binárias.

Os resultados nas funções impulso-resposta (Anexos 3 e 4) foram próximas das estimativas sem os devidos controles, o que mostra que as quebras estruturais da variável Ibovespa não afeta de forma relevante os resultados do modelo proposto inicialmente.

\section{CONSIDERAÇÕES FINAIS}

O objetivo deste trabalho foi verificar a relação entre as variáveis macroeconômicas e o índice Ibovespa no período de 2000 a 2019. As variáveis macroeconômicas selecionadas, após análises de correlação e especificações econométricas, que melhor se ajustaram foram taxa de câmbio, PIB, Reservas internacionais, taxa Selic e indicador de confiança (Quadro 2).

Uma vez selecionadas as variáveis macroeconômicas que melhores se ajustaram ao modelo, estimou-se um modelo econométrico por meio da metodologia de Vetores de Correção de Erros (VEC), metodologia utilizada em diversos estudos sobre essa temática, apresentados no Quadro 1. As evidências encontradas apontam resultados similares ao de outros estudos, com algumas constatações importantes, como a pífia resposta do Ibovespa a um impulso no PIB, diferentemente de outros trabalhos apontados na literatura. Esta relação encontrada pode estar associada a um relação inversa entre PIB e Ibovespa observado nos últimos anos no Brasil.

Entretanto, as conclusões de maior relevância são quanto a função de resposta das variáveis macroeconômicas a impulsos no Ibovespa. Em conformidade com a literatura, os resultados apresentados corroboram com os estudos que asseveram que o mercado de capitais é um municiador de recursos permanentes para a economia, pois as variáveis 
macroeconômicas estão mais fortemente ligadas ao mercado acionário. Diante de tal evidência, conclui-se que o índice Ibovespa responde melhor ao papel de variável explicativa do que ao de variável explicada.

Por fim, as evidências encontradas neste trabalho são úteis não só pela estimação de um modelo VEC e todas as contribuições que dele advém entre a relação do mercado de capitais e variáveis macroeconômicas, mas além disso, pela seleção das melhores variáveis de controle e pela determinação do índice Ibovespa como uma variável explicativa para o crescimento econômico dos países. É importante mencionar que existe uma limitação neste estudo no que diz respeito ao dinamismo do mercado acionário. A introdução de novos modelos de negócios, novas trocas financeiras, a existência de muitos mercados especulativos, novas ofertas acionárias e até mesmo a alteração de perfil dos investidores brasileiros pode fazer com que as relações de longo prazo entre as variáveis macroeconômicas e o mercado financeiro se alterem, exigindo, portanto, constantes avaliações empíricas. Em termos práticos, foi possível observar a grande relevância dos mercados de capitais para a economia, uma vez que possui relação direta com as variáveis macroeconômicas. Portanto, os resultados evidenciados por este trabalho são de fundamental importância para investidores, policymakers, empresários e demais agentes econômicos, uma vez que fornece fundamentos sobre a relação entre mercado acionário e variáveis macroeconômicas.

Portanto, este estudo interessa aos players do mercado acionário e aos policy makers. Aos players do mercado acionário porque indica quais variáveis macroeconômicas tem efeitos no Ibovespa, principal medida de desempenho das companhias de capital aberto e, de certo modo, do fluxo financeiro e de valorização das empresas, contribuindo para decisões corporativas de investimentos, emissão de ações, hedge, por exemplo. Também interessa aos policy makers porque indica como as políticas econômicas relacionadas à câmbio, reservas internacionais e taxa de juros (Selic) podem impactar o mercado acionário. Desse modo, este estudo contribui para elaboração de políticas micro e macroeconômicas que promovem a interação Estado e Empresas.

Contudo, em um contexto de plena ascenção do mercado acionário, considerando que os dados da pesquisa se referem ao perídoo de janeiro de 2000 a fevereiro de 2019 , esta aplicação empírica não esgota a agenda de pesquisa sobre essa temática, sendo cada vez mais importante investigar os determinantes do crescimento do mercado acionário no Brasil ou sua desaceleração, seja por variáveis externas ou internas à economia brasileira ou fatores não econômicos, tal como a pandemia COVID-19, mas que afeta o desenvolvimento econômico dos países. Para futuras pesquisas, recomenda-se a aplicação de modelos que visam captar variações diárias do mercado, aumentando o número de observações, gerando maior precisão sobre os determinantes destas variações. Outra possibilidade de pesquisas futuras é considerar variáveis como o Índice de Incerteza Política; ciclos políticos, especialmente, no Poder Executivo Federal; o índice de globalização, o risco Brasil, total de investimento, entre outras. Todavia incluir essas variáveis pode implicar em outro modelo econométrico. Além disso, este trabalho não avalia questões relativas aos impactos setoriais. Em outras palavras, alguns setores econômicos podem ser mais afetados por desequilíbrios econômicos e, portanto, as variáveis macroeconômicas podem exercer maior relevância na variação do preço das ações dessas empresa. Dessa forma, visualiza-se análises do impacto das variáveis econômicas no preço das ações das empresas seccionadas por setor como um promissor campo de pesquisa.

\section{REFERÊNCIAS}

Aga, M., \& Kocaman, B. E. R. N. A. (2006). An empirical investigation of the relationship between inflation, P/E ratios and stock price behaviors using a new series called Index-20 for Istanbul Stock Exchange. International Research Journal of Finance and Economics, $6(3), 133-165$.

Ameer, R. (2012). MACROECONOMIC FACTORS AND INITIAL PUBLIC OFFERINGS (IPOs) IN MALAYSIA. Asian Academy of Management Journal of Accounting \& Finance, 8(1).

Assaf-Neto, A. (2017). Mercado Financeiro. São Paulo: Atlas. 7th ed.

Bacen, Banco Central do Brasil. (2019). Sistema Gerenciador de Séries Temporais. Recuperado April 13, 2019, from https:// www3.bcb.gov.br/sgspub

Bernardelli, L. V., \& Bernardelli, A. G. (2016). Análise sobre a Relação do Mercado Acionário com as Variáveis Macroeconômicas no Período de 2004 a 2014. Revista Evidenciação Contábil \& Finanças, 4(1), 4-17.

Bernardelli, L. V., Bernardelli, A. G., \& de Castro, G. H. L. (2017). A Influência das Variáveis Macroeconômicas e do Índice de Expectativas no Mercado Acionário Brasileiro: Uma Análise Empírica para os Anos de 1995 a 2015. Revista de Gestão, Finanças e Contabilidade, 7(1), 78-96.

Bernardelli, L. V., \& de Castro, G. H. L. (2020). Mercado acionário e variáveis macroeconômicas: evidências para o Brasil. Revista Catarinense de Ciência Contábil, 19, 2892.

B3, Brasil, Bolsa e Balcão. (2019). Índice Bovespa (Ibovespa) Recuperado April 13, 2019, from http://www.bmfbovespa.com.br/ pt_br/produtos/indices/indices-amplos/indice-bovespa-ibovespa.htm

Brondani, E. L. A., Baggio, D. K., Agudo, L. F., \& Sanjuán, I. M. (2013). Influência do índice Dow Jones industrial average sobreo índice Ibovespa. Horizontes Empresariales, 12(2), 23-44.

Bueno, R. L. S. (2011). Econometria de Séries Temporais. 2. ed. São Paulo: Cengage Learning. 
da Silva Ribeiro, A. A., Leite, Á. R., \& Justo, W. R. (2016). Análise de cointegração e causalidade entre variáveis macroeconômicas e o índice Dow Jones sobre o Ibovespa. Revista de Administração da Universidade Federal de Santa Maria, 9(1), 121-137. 273-278.

Darrat, A. F., \& Mukherjee, T. K. (1986). The behavior of the stock market in a developing economy. Economics Letters, 22(2-3),

Dickey, D., Jansen, D. E., \& Thornton, D. (2007). A primer on cointegration with an application to money and income. In: Rao, B. (ed.), Cointegration for the applied economist. New York City: Palgrave Macmillan. 2nd ed, p. 9-45.

ENDERS, W. (2014). Applied Econometric Time Series (4a ed). Nova York: Wiley.

Engle, R. F., Ghysels, E., \& Sohn, B. (2013). Stock market volatility and macroeconomic fundamentals. Review of Economics and Statistics, 95(3), 776-797.

Fama, E. (1980). Banking in theory of finance. Journal of Monetary Economics, 6.

Feldstein, M. S. (1999). Self-Protection for Emerging Market Economies. NBER Working Paper, W6907.

Fonseca, M. B., Paixao, M. C., \& Maia, S. F. (2008). Previsão de produção do etanol brasileiro para exportação: uma aplicação de Vetores Auto-Regressivos (VAR). In: In: XLVI Congresso da Sociedade Brasileira de Economia, Administração e Sociologia Rural. (No. 1349-2016-107152).

Gan, C., Lee, M., Yong, H. H. A., \& Zhang, J. (2006). Macroeconomic variables and stock market interactions: New Zealand evidence. Investment management and financial innovations, 3(4), 89-101. $1-33$.

Geske, R., \& Roll, R. (1983). The fiscal and monetary linkage between stock returns and inflation. The journal of Finance, 38(1),

Gjerde, O., \& Saettem, F. (1999). Causal relations among stock returns and macroeconomic variables in a small, open economy. Journal of International Financial Markets, Institutions and Money, 9(1), 61-74.

Granger, C. W. (1969). Investigating causal relations by econometric models and cross-spectral methods. Econometrica: Journal of the Econometric Society, 424-438.

Grôppo, G. S. (2004). Causalidade das variáveis macroeconômicas sobre o Ibovespa. Dissertação (Mestrado), Escola Superior de Agricultura Luiz de Queiroz, USP, Piracicaba, p. 107.

Grôppo, G. S. (2005). Relações dinâmicas entre um conjunto selecionado de variáveis macroeconômicas e o Ibovespa. Revista de Economia e Administração, 4(4).

Gujarati, D. N., \& Porter, D. C. (2011). Econometria Básica. 5th ed. Porto Alegre: Bookman.

Gurley, J. G., \& Shaw, E. S. (1955). Financial aspects of economic development. The American Economic Review, 45(4), 515-538.

IPEADATA. (2019). Dados Macroeconômicos. (2019). Recuperado April 13, 2019, from http://www.ipeadata.gov.br/Default.aspx

Keynes, J. M. (1988). A Teoria Geral do Emprego do Juro e da Moeda. São Paulo: Nova Cultural.

Kothari, S. P. (2001). Capital markets research in accounting. Journal of accounting and economics, 31(1-3), 105-231.

Machado, M. R. R., Gartner, I. R., \& de Souza Machado, L. (2017). Relação entre Ibovespa e Variáveis Macroeconômicas: Evidências a Partir de um Modelo Markov-Switching. Revista Brasileira de Finanças, 15(3), 435-468.

Maysami, R. C., \& Koh, T. S. (2000). A vector error correction model of the Singapore stock market. International Review of Economics \& Finance, 9(1), 79-96.

Meurer, R. (2006). Custo na dívida pública interna da redução da vulnerabilidade externa

brasileira através do aumento das reservas internacionais. Análise Econômica, 24(46), 41.

Minsky, H. (1986). Stabilizing an unstable economy. New Haven: Yale University Press.

Morettin, P. A.; Toloi, C. (2006). Análise de séries temporais. Blucher.

Mukherjee, T. K., \& Naka, A. (1995). Dynamic relations between macroeconomic variables and the Japanese stock market: an application of a vector error correction model. Journal of Financial Research, 18(2), 223-237.

Oliveira, J. D. C. T., \& Frascaroli, B. F. (2014). Impacto dos fatores macroeconômicos na emissão de ações na bolsa de valores. Revista de Gestão, Finanças e Contabilidade, 4(1), 30-51.

Oliveira, L. O. G. de. (2006). Análise empírica da relação entre mercado acionário e variáveis macroeconômicas: de 1972 a 2003.2006. 113 f. Dissertação (Mestrado) - Curso de Economia, Universidade Federal de Santa Catarina, Florianópolis.

Paula, L. F. (2014). Sistema Financeiro, Bancos e Financiamento da Economia: Uma Abordagem Keynesiana. Rio de Janeiro. Campus Elsevier.

Perales, N. A. H.; Robins, R. (2002). The relationships between Mexican Stock Market returns and real, monetary and economic variables. Manuscript, ITESM, Graduate School of Business Administration and leadership, Monterrey, Mexico.

Junior, T. P., \& Higuchi, R. H. (2008). Variáveis macroeconômicas e o Ibovespa: um estudo da relação de causalidade. REAd-Revista Eletrônica de Administração, 14(2), 296-315.

Singh, D. (2010). Causal Relationship Between Macro-Economic Variables and Stock Market: A Case Study for India. Pakistan Journal of Social Sciences (PJSS), 30(2). 
Singh, T., Mehta, S., \& Varsha, M. S. (2011). Macroeconomic factors and stock returns: Evidence from Taiwan. Journal of economics and international finance, 3(4), 217-227.

Wright, J. H. (1998). Testing for a structural break at unknown date with long-memory disturbances. Journal of Time Series Analysis, 19(3), 369-376.

\section{ANEXOS}

Anexo 1 - Resumo dos Testes de Raiz Unitária aos Níveis de significância de 1\%, 5\% e 10\%

\begin{tabular}{|c|c|c|c|c|c|c|c|}
\hline & VARIÁVEL & TERMO & EST_T & $1 \%$ & $5 \%$ & $10 \%$ & DECISÃO \\
\hline \multirow{12}{*}{$\mathrm{ADF}$} & Ibovespa & $\mathrm{t}, \mathrm{c}$ & $-1,621$ & $-3,998$ & $-3,429$ & $-3,138$ & Não Estacionário \\
\hline & Ibovespa (1) & $\mathrm{t}, \mathrm{c}$ & $-13,403$ & $-3,998$ & $-3,429$ & $-3,138$ & Estacionário \\
\hline & Câmbio & $\mathrm{t}, \mathrm{c}$ & $-2,269$ & $-3,998$ & $-3,429$ & $-3,138$ & Não Estacionário \\
\hline & Câmbio (1) & $\mathrm{t}, \mathrm{c}$ & $-11,487$ & $-3,998$ & $-3,429$ & $-3,138$ & Estacionário \\
\hline & PIB & $\mathrm{t}, \mathrm{c}$ & $-0,520$ & $-3,998$ & $-3,429$ & $-3,138$ & Não Estacionário \\
\hline & PIB (1) & $\mathrm{t}, \mathrm{c}$ & $-3,557$ & $-3,998$ & $-3,429$ & $-3,138$ & Estacionário \\
\hline & Reserva & $\mathrm{t}, \mathrm{c}$ & $-0,314$ & $-3,998$ & $-3,429$ & $-3,138$ & Não Estacionário \\
\hline & Reserva (1) & $\mathrm{t}, \mathrm{c}$ & $-7,764$ & $-3,998$ & $-3,429$ & $-3,138$ & Estacionário \\
\hline & Selic & $\mathrm{t}, \mathrm{c}$ & $-2,941$ & $-3,998$ & $-3,429$ & $-3,138$ & Não Estacionário \\
\hline & Selic (1) & $\mathrm{t}, \mathrm{c}$ & $-4,133$ & $-3,998$ & $-3,429$ & $-3,138$ & Estacionário \\
\hline & Confiança & $\mathrm{t}, \mathrm{c}$ & $-1,919$ & $-3,998$ & $-3,429$ & $-3,138$ & Não Estacionário \\
\hline & Confiança (1) & $\mathrm{t}, \mathrm{c}$ & $-15,155$ & $-3,998$ & $-3,429$ & $-3,138$ & Estacionário \\
\hline \multirow{12}{*}{ PP } & Ibovespa & $\mathrm{t}, \mathrm{c}$ & $-1,775$ & $-3,998$ & $-3,429$ & $-3,138$ & Não Estacionário \\
\hline & Ibovespa (1) & $\mathrm{t}, \mathrm{c}$ & $-13,378$ & $-3,998$ & $-3,429$ & $-3,138$ & Estacionário \\
\hline & Câmbio & $\mathrm{t}, \mathrm{c}$ & $-2,222$ & $-3,998$ & $-3,429$ & $-3,138$ & Não Estacionário \\
\hline & Câmbio (1) & $\mathrm{t}, \mathrm{c}$ & $-11,658$ & $-3,998$ & $-3,429$ & $-3,138$ & Estacionário \\
\hline & PIB & $\mathrm{t}, \mathrm{c}$ & $-2,233$ & $-3,998$ & $-3,429$ & $-3,138$ & Não Estacionário \\
\hline & PIB (1) & $\mathrm{t}, \mathrm{c}$ & $-25,855$ & $-3,998$ & $-3,429$ & $-3,138$ & Estacionário \\
\hline & Reserva & $\mathrm{t}, \mathrm{c}$ & $-0,691$ & $-3,998$ & $-3,429$ & $-3,138$ & Não Estacionário \\
\hline & Reserva (1) & $\mathrm{t}, \mathrm{c}$ & $-14,913$ & $-3,998$ & $-3,429$ & $-3,138$ & Estacionário \\
\hline & Selic & $\mathrm{t}, \mathrm{c}$ & $-3,630$ & $-3,998$ & $-3,429$ & $-3,138$ & Não Estacionário \\
\hline & Selic (1) & $\mathrm{t}, \mathrm{c}$ & $-25,136$ & $-3,998$ & $-3,429$ & $-3,138$ & Estacionário \\
\hline & Confiança & $\mathrm{t}, \mathrm{c}$ & $-1,932$ & $-3,998$ & $-3,429$ & $-3,138$ & Não Estacionário \\
\hline & Confiança (1) & $\mathrm{t}, \mathrm{c}$ & $-15,157$ & $-3,998$ & $-3,429$ & $-3,138$ & Estacionário \\
\hline
\end{tabular}




\begin{tabular}{|c|c|c|c|c|c|c|c|}
\hline & VARIÁVEL & TERIMO & EST_T & $1 \%$ & $5 \%$ & $10 \%$ & DECISÃO \\
\hline \multirow{11}{*}{ KPSS } & Ibovespa & $\mathrm{t}, \mathrm{c}$ & 0,349 & 0,216 & 0,146 & 0,119 & Não Estacionário \\
\hline & Ibovespa (1) & $\mathrm{t}, \mathrm{c}$ & 0,087 & 0,216 & 0,146 & 0,119 & Estacionário \\
\hline & Câmbio & $\mathrm{t}, \mathrm{c}$ & 0,281 & 0,216 & 0,146 & 0,119 & Não Estacionário \\
\hline & Câmbio (1) & $\mathrm{t}, \mathrm{c}$ & 0,062 & 0,216 & 0,146 & 0,119 & Estacionário \\
\hline & PIB & $\mathrm{t}, \mathrm{c}$ & 0,380 & 0,216 & 0,146 & 0,119 & Não Estacionário \\
\hline & PIB (1) & $\mathrm{t}, \mathrm{c}$ & 0,236 & 0,216 & 0,146 & 0,119 & Estacionário \\
\hline & Reserva & $\mathrm{t}, \mathrm{c}$ & 0,366 & 0,216 & 0,146 & 0,119 & Não Estacionário \\
\hline & Reserva (1) & $\mathrm{t}, \mathrm{c}$ & 0,204 & 0,216 & 0,146 & 0,119 & Estacionário \\
\hline & Selic & $\mathrm{t}, \mathrm{c}$ & 0,128 & 0,216 & 0,146 & 0,119 & Estacionário \\
\hline & Confiança & $\mathrm{t}, \mathrm{c}$ & 0,391 & 0,216 & 0,146 & 0,119 & Não Estacionário \\
\hline & Confiança (1) & $\mathrm{t}, \mathrm{c}$ & 0,073 & 0,216 & 0,146 & 0,119 & Estacionário \\
\hline
\end{tabular}

Fonte: Elaborado pelos autores (2020).

Anexo 2 - Funções de resposta a impulso nas variáveis macroeconômicas (considerando as quebras estruturais)

Resposta a uma variação de um desvio padrão
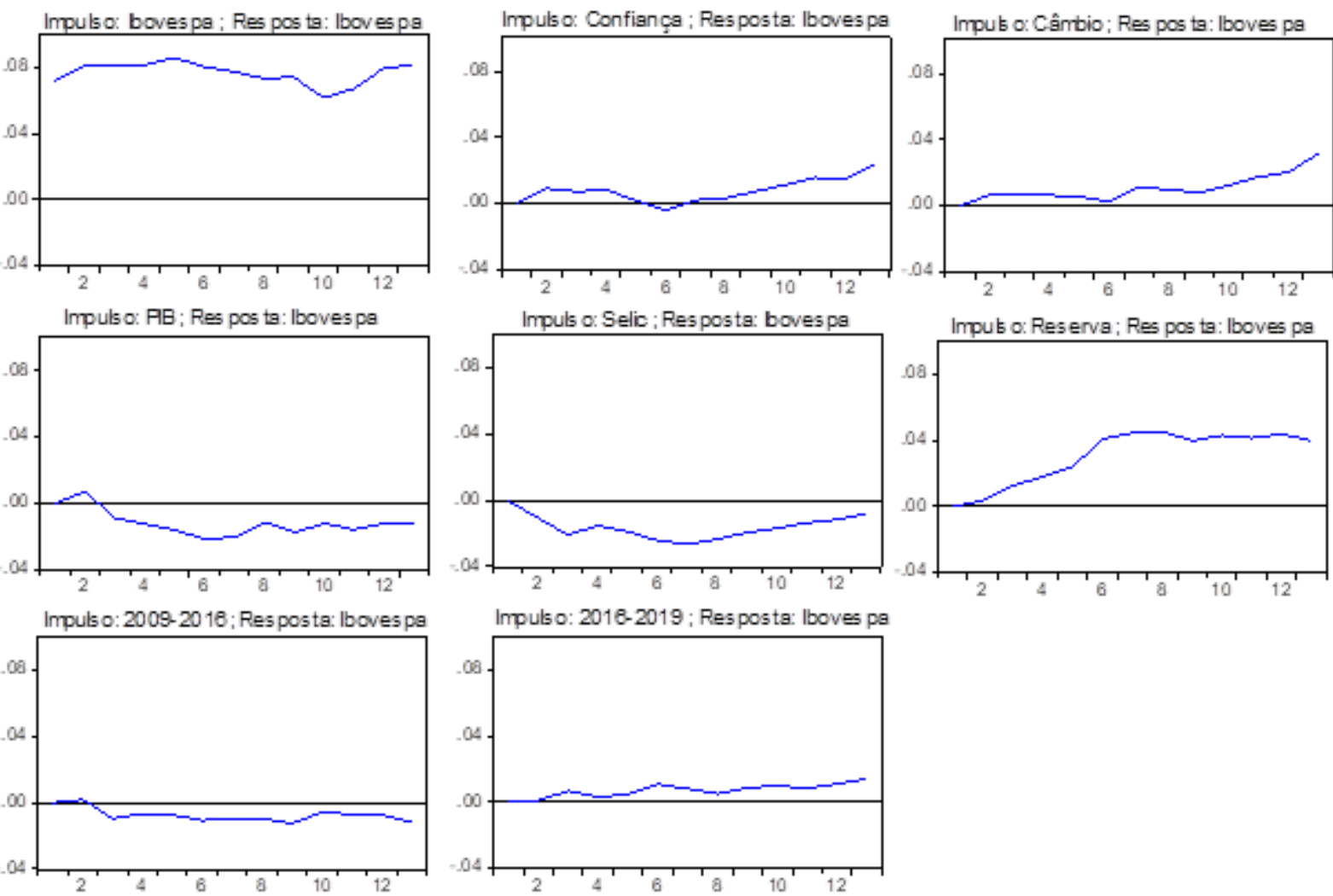

Fonte: Elaborado pelos autores (2020). 
Anexo 3 - Funções de resposta a impulso nas variáveis macroeconômicas (considerando as quebras estruturais).

Resposta a uma variação de um desvio padrão
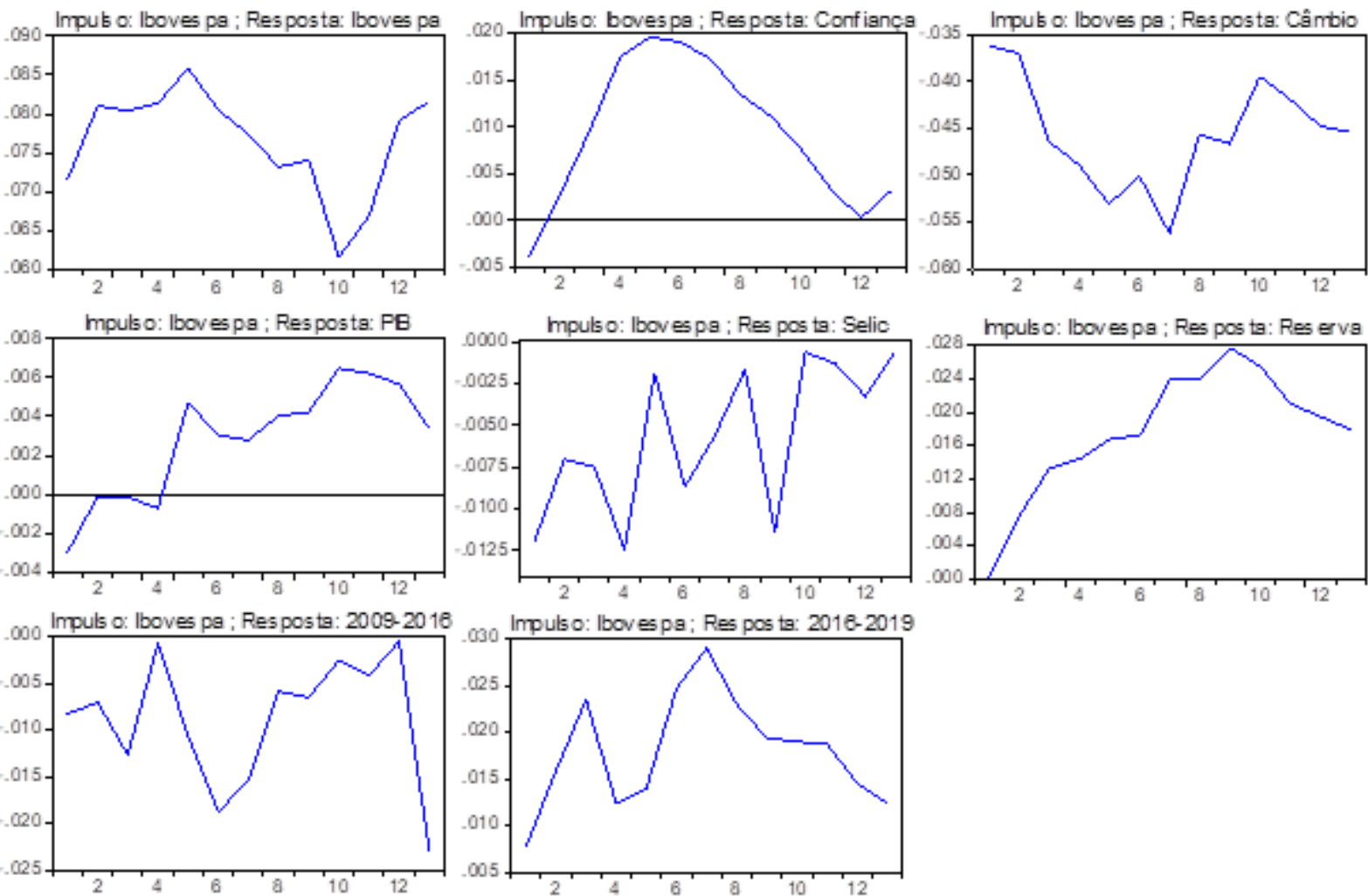

Fonte: Elaborado pelos autores (2020).

Anexo 3 - Descrição completa das variáveis utilizadas no modelo

\begin{tabular}{|c|c|c|}
\hline Variável & Descrição & Fonte \\
\hline Valor Ibovespa & Bovespa - índice mensal - Pontos - (Logaritmizado) & $\begin{array}{l}\text { BACEN (2019) } \\
\text { Série } 7845\end{array}$ \\
\hline Câmbio & $\begin{array}{l}\text { Índice da taxa de câmbio real efetiva (IPCA) - } \\
\text { Jun/1994=100 }\end{array}$ & BACEN (2019) - Série 11752 \\
\hline PIB & $\begin{array}{c}\text { PIB mensal - Valores correntes (R\$ milhões) - R\$ (milhões) - } \\
\text { Deflacionado pelo IPCA (Logaritmizado) }\end{array}$ & BACEN (2019) - Série 4380 \\
\hline Reserva & $\begin{array}{c}\text { Reservas internacionais - Conceito liquidez - Total - mensal } \\
\text { - US\$ (milhões) (Logaritmizado) }\end{array}$ & BACEN (2019) - Série 3546 \\
\hline Selic & Taxa de juros: Overnight / Selic (Logaritmizado) & IPEA (2019) \\
\hline Confiança & $\begin{array}{l}\text { Índice de Confiança do Consumidor - Índice } \\
\text { (Logaritmizado) }\end{array}$ & BACEN (2019) - Série 4393 \\
\hline
\end{tabular}

Fonte: elaborado pelos autores (2020). 